\title{
Fixation of Dinitrogen at an Asymmetric Binuclear Titanium $\mathrm{N}_{2}$ Complex
}

\author{
Dae Young Bae, Gunhee Lee, and Eunsung Lee* \\ Dedication ((optional))
[*] D. Y. Bae, G. Lee, Prof. E. Lee
Department of Chemistry
Pohang University of Science and Technology
77 Cheongam-Ro, Nam-Gu, Pohang, Gyeongbuk, Republic of Korea, 37673 \\ E-mail: eslee@postech.ac.kr \\ Supporting information for this article is given via a link at the end of the document.((Please delete this text if not appropriate))
}

\begin{abstract}
A new type of dinitrogen dititanium complex supported by a triphenolamine (TPA) ligand is reported. Analysis by single-crystal X-ray diffraction, Raman, and NMR spectroscopy reveals different coordination geometries for the two titanium centers. Hence, coordination of TPA and a nitrogen ligand results in trigonal bipyramidal geometry while an octahedral titanium center is obtained upon additional coordination of an ethoxide generated upon $\mathrm{C}-\mathrm{O}$ bond cleavage in a diethyl ether solvent molecule. The titanium complex successfully generates ammonia in presence of an excess amount of $\mathrm{PCy}_{3} \mathrm{HI}$ and $\mathrm{KC}_{8}$ in $154 \%$ yield (per Ti atom). A titanium complex with a bulkier TPA does not form a $\mathrm{N}_{2}$ complex and mononuclear titanium $\mathrm{N}_{2}$ complexes were not accessible, presumably due to high tendency of early transition metals to form $\mathrm{N}_{2}$ binuclear complexes.
\end{abstract}

Molecular dinitrogen $\left(\mathrm{N}_{2}\right)$ has been utilized as an important starting feedstock for value-added nitrogen-containing compounds such as ammonia because it is abundant, readily accessible, and inexpensive. ${ }^{[1]}$ However, the $\mathrm{N}_{2}$ molecule has one of the highest bond-dissociation energy known (226 $\mathrm{kcal} / \mathrm{mol}$ ), poor $\sigma$-donating and $\pi$-accepting abilities, large HOMO (-15.6 eV)-LUMO (+7.3 eV) energy difference, and nonpolarized character..$^{[2]}$ In nature, production of ammonia from $\mathrm{N}_{2}$ under ambient conditions is achieved by metalloenzymes. Haber-Bosch process, which produces ammonia from $\mathrm{N}_{2}$ on an industrial-scale - more than 160 million tons annually, is a highly energy-intensive process mainly due to the inertness of molecular nitrogen. About $1-2 \%$ of the world's annual energy supply is needed to produce ammonia through the process. Furthermore, carbon dioxide is produced as a by-product in significantly higher yield than ammonia. ${ }^{[3]}$ Thus, this process has limitations from an energetic and environmental point of view and new methods that requires lower energy consumption and avoid $\mathrm{CO}_{2}$ production are intensively sought after. Since transition metal complexes were found to fix molecular dinitrogen effectively, transition metal catalysis for $\mathrm{N}_{2}$ reduction has been intensively studied for the past several decades. ${ }^{[4]}$ Over this time, numerous research groups have developed various systems that fix and functionalize molecular dinitrogen. ${ }^{[5]}$

Schrock and Yandulov reported the first example of the catalytic system for dinitrogen reduction to ammonia and isolated eight key intermediates of the distal pathway. ${ }^{[6]}$ The Peters group has been working on catalytic nitrogen reduction to ammonia ever since they reported the first nitrogen-fixing iron catalyst. ${ }^{[7]}$ Nishibayashi and co-workers showed a molybdenum catalyst with the highest catalytic turnover for this reaction. ${ }^{[8]}$ In addition, the same group also reported the first examples of vanadium complexes that transform nitrogen gas into tris(trimethylsilyl)amine catalytically. ${ }^{\left[{ }^{[]}\right.}$Low-valent mononuclear dinitrogen titanocene complexes were reported by the Chirik group ${ }^{[10]}$ As first examples of early transition metal catalysts for ammonia generation from $\mathrm{N}_{2}$, the Liddle group reported a titanium-triamidoamine system. ${ }^{[11]}$ Catalytic conversion of dinitrogen to tris(trimethylsilyl)amine was also explored by the Okuda group with a titanium complex. ${ }^{[12]}$ Kawaguchi developed activation/cleavage of $\mathrm{N}_{2}$ by a titanium complex, followed by the formation of nitrogen-carbon bond with various electrophiles. ${ }^{[13]}$ Hou and co-workers reported a multinuclear titanium framework that cleaves $\mathrm{N}_{2}$ and converts it to nitriles, as well as titanium PNP pincer complexes that promote cleavage, alumination, silylation, and hydrogenation of the $\mathrm{N}_{2}$ unit. ${ }^{[14]}$ The Ohki group developed a Mo-Ti-S cluster that activates $\mathrm{N}_{2}$ at the titanium center. ${ }^{[15]}$

Scheme 1. Reported end-on/end-on dinitrogen transition metal complexes and an asymmetric binuclear titanium $\mathrm{N}_{2}$ complex

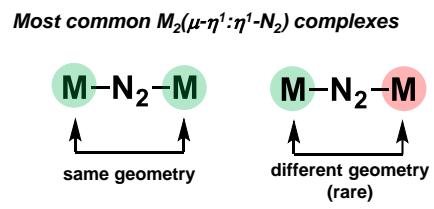

This work

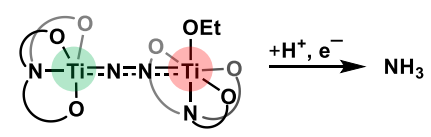

\footnotetext{
- First example of binuclear transition metal $\mathrm{N}_{2}$ complex with trigonal bipyramidal and octahedral geometries

- First triphenolamine (TPA) based $\mathrm{N}_{2}$ complex
}

Notwithstanding the significant development in the synthesis of transition metal $\mathrm{N}_{2}$ complexes, the number of known binuclear transition metal $\mathrm{N}_{2}$ complexes with a different geometry on each metal center is still limited. Especially, to the best of our knowledge, a binuclear transition metal $\mathrm{N}_{2}$ complex with octahedral and trigonal bipyramidal coordination geometries of the metal centers has never been reported. Inspired by the excellent examples of binuclear titanium $\mathrm{N}_{2}$ complexes reported by the Liddle and Kawaguchi groups, ${ }^{[11,13 a, 13 c]}$ we explored triphenolamine (TPA) as a ligand for titanium in a catalytic $\mathrm{N}_{2}$ activation reaction. TPA has been utilized as a ligand in many transition metal catalyzed reactions such as ring-opening and 
olefin polymerization, and sulfoxidation. ${ }^{[16]}$ However, TPA complexes have never been utilized for $\mathrm{N}_{2}$ activation. Herein, we report the first example of a new end-on/end-on dinitrogen dititanium TPA complex with octahedral and trigonal bipyramidal geometries capable of catalytic nitrogen reduction to ammonia.
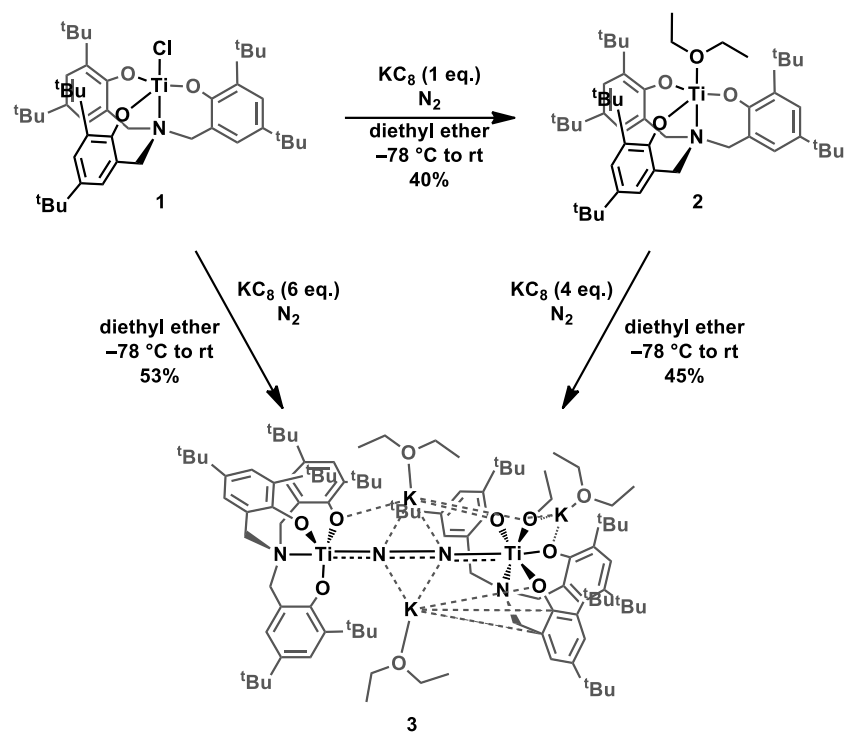

Scheme 2. Synthesis of titanium diethyl ether complex 2 and dititanium dinitrogen complex $\mathbf{3}$

Reduction of the titanium chloride complex $1^{[17]}$ supported by tris(4,6-di-tert-butyl-2-hydroxybenzyl)amine $\left(\mathbf{L 1 H}_{3}\right)$ with one equivalent of potassium graphite $\left(\mathrm{KC}_{8}\right)$ yielded light violetcolored paramagnetic $\left(1.79 \mu_{\mathrm{B}}\right)$ titanium(III) diethyl ether complex 2 (Scheme 2). The complex was purified by recrystallization from diethyl ether and single crystals of $\mathbf{2}$ were grown from the concentrated solution at room temperature. Single-crystal X-ray analysis shows that $\mathbf{2}$ adopts a trigonal bipyramidal geometry $(\tau=0.97)$; typical for the early transition metal triphenolateamine (TPA) complexes (Figure 1 (a)). ${ }^{[16]}$ The lengths of $\mathrm{Ti}-\mathrm{O}$ (ether) and $\mathrm{Ti}-\mathrm{O}_{\mathrm{avg}}$ (phenolate) bonds are 2.159(3) $\AA$ and $1.911 \AA$, respectively while the bond distance of Ti-N is 2.181(4) $\AA$. These lengths are similar to those observed in other known titanium TPA complexes. ${ }^{[16]}$ As $\mathbf{1}$ is reduced to 2 , the distance between the titanium center and the mean plane defined by the three oxygen atoms of phenolates is shortened to $0.067 \AA$ from $0.224 \AA .{ }^{[18]}$ Notably, the formation of other titanium complexes was not observed by IR or ${ }^{1} \mathrm{H}$ NMR spectroscopy (Figure S21 and S22) when 3 equivalents of $\mathrm{KC}_{8}$ were used for the reduction of 1 (vide infra).

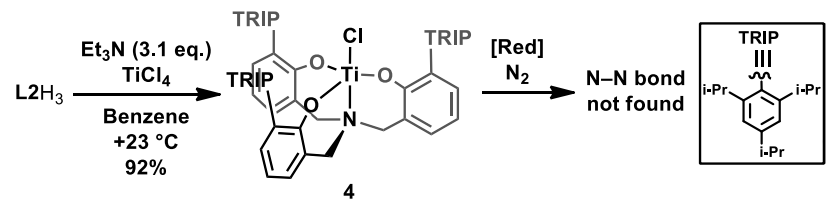

Scheme 3. Synthesis of titanium chloride complex $\mathbf{4}$ with L2 (a)

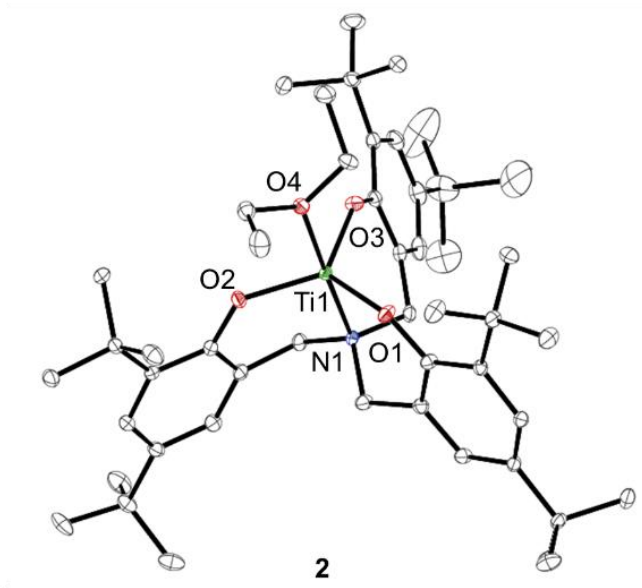

(b)

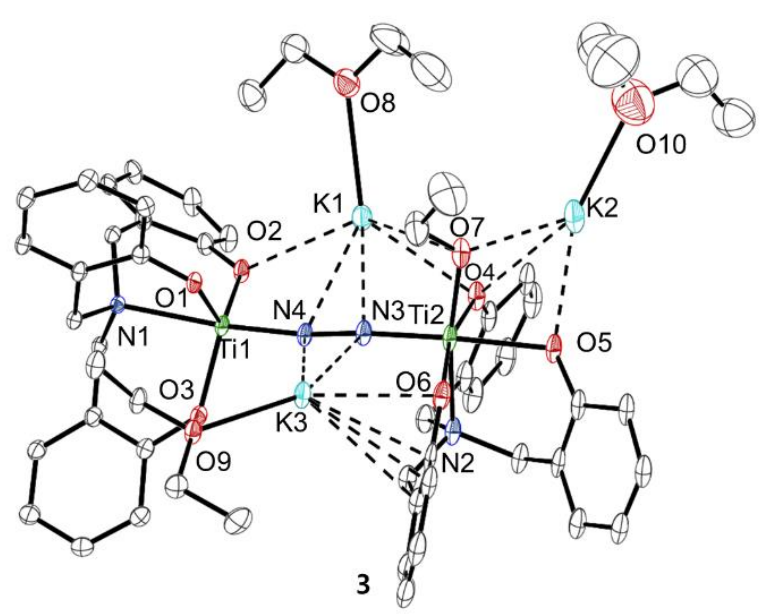

(c)

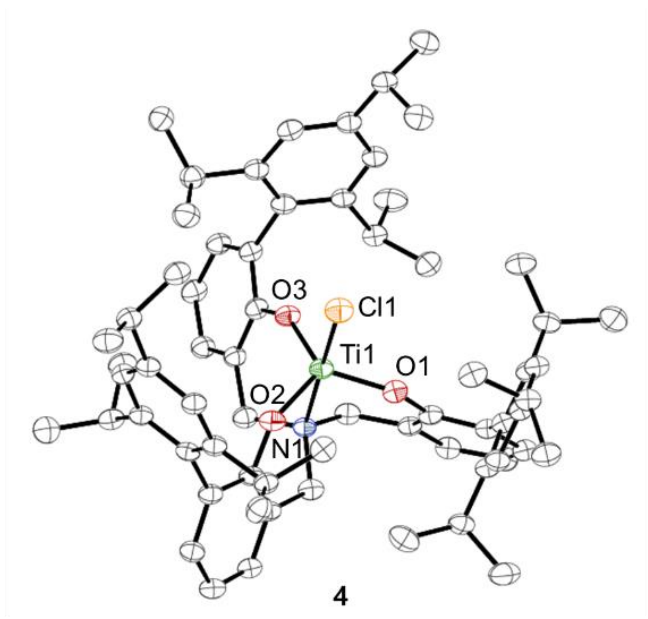

Figure 1. Crystal structures of (a) 2, (b) 3, and (c) 4 showing thermal ellipsoids at the $30 \%$ probability level. Hydrogen atoms and some ${ }^{t} \mathrm{Bu}$ groups were omitted for clarity. Selected bond lengths $(\AA)$ and angles $\left({ }^{\circ}\right)$ for complexes: 2, Ti1-01 1.868(2), Ti1-O4 2.159(3), Ti1-N1 2.181(4), N1-Ti1-O4 178.0(1), O1Ti1-O2 126.1(1), N1-Ti1-O1 86.5(1); 3, Ti1-O1 1.984(2), Ti1N1 2.258(2), Ti1-N4 1.791(3), N3-N4 1.288(4), Ti2-N3 1.803(3), Ti2-N2 2.258(5), Ti2-O5 2.156(3), O1-Ti1-O2 118.6(1), N1Ti1-N4 174.0(1), Ti1-N4-N3 172.6(3), N4-N3-Ti2 169.5(3), N3-Ti2-N2 89.1(1) N2-Ti2-O7 171.0(1), O4-Ti2-O5 81.6(1); 4, Ti1-O1 1.810(2), Ti1-N1 2.302(2), Ti1-Cl1 2.283(1), N1-Ti1Cl1 179.04(6), O1-Ti1-O2 118.46(9). 
Treatment of $\mathbf{1}$ or $\mathbf{2}$ with respectively six or four equivalents of $\mathrm{KC}_{8}$ under $\mathrm{N}_{2}$ atmosphere yielded dark brownish-purple crystals. XRD analysis revealed the structure of the dititanium complex 3 (Scheme 2), with $\mathrm{N}_{2}$ bound in a nearly linear manner (Figure 1 (b)). Interestingly, an odd (three) number of potassium ions stabilizes 3 , which results in a complex of low symmetry. One of the titanium centers adopts a trigonal bipyramidal (TBP) geometry $(\tau=0.92)$ while the other is octahedral. This combination of geometries has not been reported previously to the best of our knowledge (Table S3). Dinitrogen is bound as an end-on/end-on bridging ligand between the two titanium centers, in the axial position with respect to the TBP titanium center ( $4 \mathrm{~N} 1-$ Ti1-N4 = 174.0 $(1)^{\circ}$ ) and also positioned cis to the nitrogen atom of the TPA ligand of the octahedral titanium center ( $4 \mathrm{~N} 2-\mathrm{Ti} 2-\mathrm{N} 3$ $\left.=89.1(1)^{\circ}\right)$.

The Schrock group demonstrated that molybdenum $\mathrm{N}_{2}$ complexes could be obtained either as mononuclear or binuclear complexes, depending on the steric congestion of their ligand scaffolds. ${ }^{[6 a, 6 e, 6 t, 19]}$ Inspired by these results, we sought to investigate the steric effect of the TPA scaffold on $\mathrm{N}_{2}$ binding. Hence, the ortho tert-butyl substituents were changed to 2,4,6triisopropylphenyl (TRIP) groups in ligand $\mathbf{L 2 H}_{3}$ (Scheme 3), studied previously by our group. ${ }^{[20]}$ In a subsequent step, we expected to observe a mononuclear L2Ti- $\mathrm{N}_{2}$ complex due to the sterically congested environment on the titanium center. To validate this hypothesis, a titanium complex $\mathbf{4}$ carrying the $\mathbf{L 2}$ ligand was prepared and its reactivity towards dinitrogen investigated (Scheme 3). XRD analysis of 4 (Figure 1 (c)) provided the depth of the cavity, which is defined as the distance from the titanium center to the mean plane of the furthest $\mathrm{Pr}$ hydrogen atoms blocking the cavity, is $\sim 5.743 \AA$ which is enough to hinder the formation of binuclear titanium $\mathrm{N}_{2}$ complexes. However, despite extensive efforts, we could not obtain any dinitrogen complexes starting from 4 . This result indicates the strong tendency of early transition metals such as titanium to activate dinitrogen preferentially as binuclear complexes. Consequently, a mononuclear titanium dinitrogen complex bearing $\mathbf{L} 2$ was not obtained even in the presence of the bulky TRIP groups. ${ }^{[21]}$

The $\mathrm{N}-\mathrm{N}$ bond of 3 is elongated to $1.288(4) \AA$, which is closer to the standard length of the $\mathrm{N}-\mathrm{N}$ double bonds $(1.240 \AA$ ) , from $1.098 \AA$ in molecular dinitrogen and falls within the range reported for other binuclear titanium $N_{2}$ complexes. ${ }^{[11-13,15,22]}$ However, it is among the shortest $\mathrm{N}-\mathrm{N}$ bond distances observed in bridged $\mathrm{N}_{2} \mathrm{~K}_{2}$ binuclear titanium complexes so far. ${ }^{[11-13,15]}$ The $\mathrm{Ti}-\mathrm{N}_{2}$ bonds (Ti1-N4 1.791(3), Ti2-N3 1.803(3) $\AA$ ) are shortened revealing partial titanium-imido character. The titanium ion of TBP geometry in $\mathbf{3}$ is located $0.239 \AA$ above the mean plane defined by the three phenolates as it is re-oxidized to $\mathrm{Ti}^{\mathrm{IV}}$.

Simultaneously with dinitrogen ligand coordination, an ethoxide ligand binds to one of the titanium centers trans to the amine nitrogen of the TPA ligand, resulting in an octahedral geometry. Ethoxide generation from diethyl ether (solvent) and potassium graphite via $\mathrm{C}-\mathrm{O}$ bond cleavage is well-documented in the literature. ${ }^{[13 b, 23]}$ To further verify the presence of the ethoxide ligand, 3 was reacted with TMSOTf providing TMSOEt, as observed by ${ }^{1} \mathrm{H}$ NMR spectroscopy (Figure S23). Due to the $\mathrm{C}-\mathrm{O}$ bond cleavage, more equivalents of $\mathrm{KC}_{8}$ are needed to afford 3 than expected for the molecular dinitrogen capture process alone. All attempts to obtain intermediates anticipated during the formation of complex $\mathbf{3}$ from 2 failed. Furthermore, replacing potassium graphite with sodium (up to 6 equiv.) in the reduction of 1 yielded titanium diethyl complex 2 exclusively.

We believe that the change in titanium coordination geometry from TBP to octahedral in $\mathbf{3}$ is crucial for nitrogen binding due to the high steric hindrance of the active site caused by the tBu groups of L1. In case of $\mathbf{2}$, the depth of the cavity, defined as the distance from the titanium center to the mean plane of the furthest ${ }^{\mathrm{t}} \mathrm{Bu}$ hydrogen atoms blocking the cavity, ${ }^{[24]}$ is approx. $\sim 2.496 \AA$. Therefore, 2 is too congested to accumulate a bridging $\mathrm{N}_{2} \mathrm{~K}_{2}$ ligand between the titanium centers while maintaining TBP geometry on each metal center. In comparison, when the titanium center of 3 changes its geometry to octahedral the depth of the cavity decreases to $\sim 1.123 \AA$ toward the trans amine nitrogen, and the depth of the cavity of the opposite TBP center is also decreased to $2.144 \AA$. In comparison, in Kawaguchi's $\left[\mathrm{TiO}_{3}\right]$ analogous complex, ${ }^{[13 a]}$ the starting complex shows lower cavity depth $(\sim 1.125 \AA)$, which decreases to $\sim 0.891$ and $\sim 0.900 \AA$, respectively, as it transforms to the binuclear titanium $\mathrm{N}_{2}$ complex of high symmetry. Even though our system is structurally similar to Kawaguchi's system, the depth of the cavity is different because of the chelating ligand ring size. While six-membered rings are present in the case of complex 3 , the Kawaguchi system features five-membered rings resulting in a less hindered metal center.

(a)

(b)

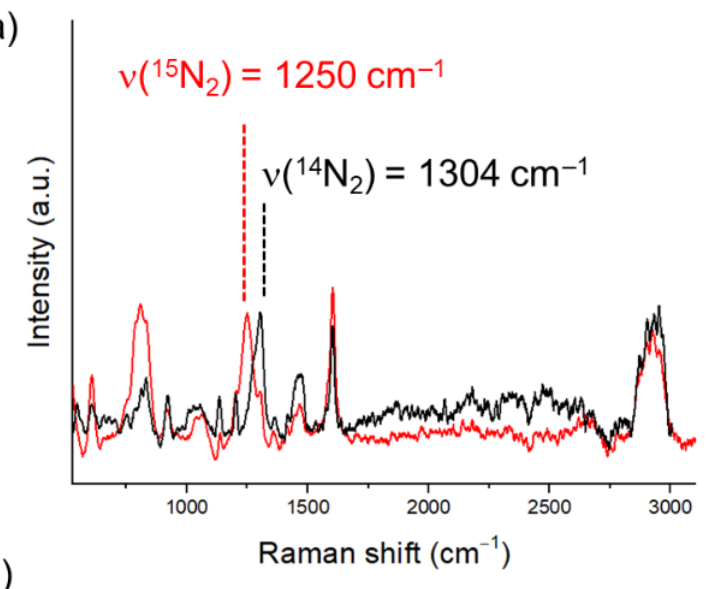

411.08

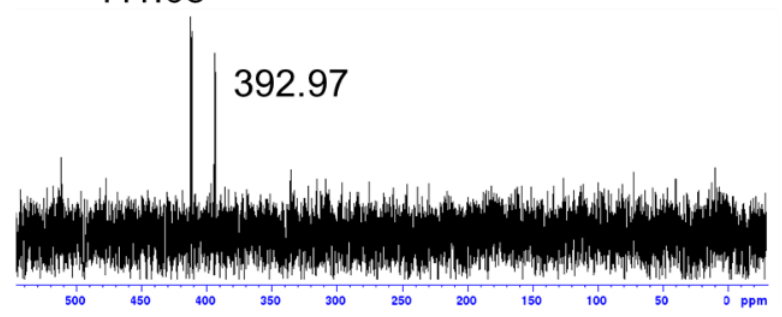

Figure 2. Selected spectral data of 3. (a) Raman spectra of 3 (black) and $3-{ }^{15} \mathrm{~N}_{2}$ (red). (b) ${ }^{15} \mathrm{~N}$ NMR spectrum (86.2 MHz) of 3${ }^{15} \mathrm{~N}_{2}$.

In a Raman spectrum of $\mathbf{3}$ the $(\mathrm{N}-\mathrm{N})$ band is observed at $1304 \mathrm{~cm}^{-1}$ which indicates a high degree of activation of the $\mathrm{N}_{2}$ ligand (Figure $2(\mathrm{a}))$. The corresponding $v\left({ }^{15} \mathrm{~N}-{ }^{15} \mathrm{~N}\right)$ band of 3${ }^{15} \mathrm{~N}_{2}$ is observed at $1250 \mathrm{~cm}^{-1}$, as expected due to isotope effects. ${ }^{[25]}$ The $\mathrm{N}-\mathrm{N}$ band could not be observed by IR spectroscopy due to low IR activity and the presence of various 
peaks in the fingerprint region. ${ }^{19 a]}$ The ${ }^{15} \mathrm{~N}$ NMR spectrum of the enriched ${ }^{15} \mathrm{~N}_{2}$ isotopologue ${ }^{3-{ }^{-15}} \mathrm{~N}_{2}$ features two doublets at $\delta=$ 411.08 and 392.97 (Figure 2 (b)) unlike one singlet observed in symmetric dinuclear $\mathrm{N}_{2}$ complexes. The diamagnetic character is consistent with the $\mathrm{TiV}^{\mathrm{IV}} / \mathrm{Ti}^{\mathrm{IV}} / \mathrm{N}_{2}{ }^{4-}$ formulation, which is also supported by DFT calculations.

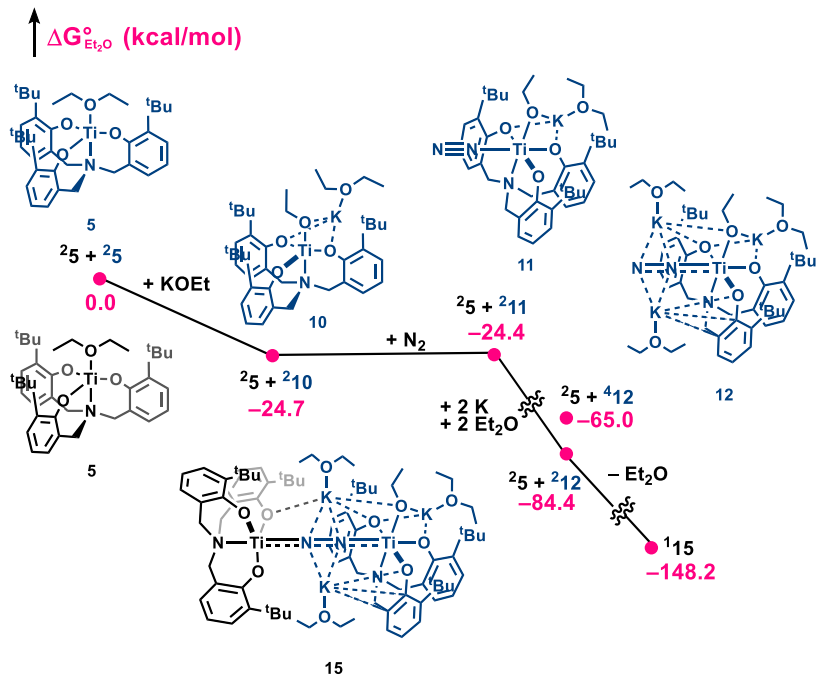

Scheme 4. Thermodynamic profile of a feasible mechanism for the formation of the titanium dinitrogen complex with schematic structures and relative free energies $(\mathrm{kcal} / \mathrm{mol})$ computed at the $\mathrm{M} 06 \mathrm{~L} / \mathrm{BSI} / / \mathrm{BSII}, \mathrm{SMD}$ level in the solution $\left(\mathrm{Et}_{2} \mathrm{O}\right)$ phase. Ground state energies are relative to the sum of 2 equivalents of 5 . Superscripts indicate spin multiplicities.

DFT calculations were used to better understand the electronic properties and formation mechanism of $\mathbf{3}$ with a simplified ligand system (para tert-butyl groups of L1 were replaced by hydrogen atoms for computational efficiency). Compound 15 (Scheme 4), which is equivalent to 3 , exhibits near-degenerated $\mathrm{HOMO}$ and HOMO-1 orbitals $(\Delta \mathrm{E}=-2.80$ $\mathrm{kcal} / \mathrm{mol}$ ) that are orthogonal and can be interpreted in terms of $\mathrm{Ti} \rightarrow \mathrm{N}_{2} \pi^{*}$ back bonding interactions (Figure S25). The titanium atoms transferred their electrons through the $\mathrm{dm}$ electron density to the $\pi^{*}$ orbitals on the $\mathrm{N}_{2}$ ligand. It should be noted that the $\mathrm{z}$ axis of Ti2 in $\mathbf{1 5}$ is along the N3-Ti2-O5 bond in contrast to the starting compounds 1 and 2 (N1-Ti1-Cl1/N1-Ti1-O4), so that $\pi$ back bonding from $\mathrm{Ti} 2$ to $\mathrm{N}_{2}$ ligand is possible. Consequently, the calculated $\mathrm{N}-\mathrm{N}$ stretching frequency is significantly lower $\left(1430 \mathrm{~cm}^{-1}\right)$ compared to unbound nitrogen. The antibonding contribution to the Ti2-O5 interaction results in a relatively long bond (Ti2-O5 = 2.177 $\AA$ ), as observed in the crystal structure of 3 (Ti2-O5 = 2.156(3) $\AA$ ). In addition, the calculated Mayer bond orders of Ti1-N4, N4-N3, and Ti2-N3 of 15 are 1.41, 1.31, and 1.30 , respectively, in good agreement with the bond lengths of Ti1-N4, N4-N3, and Ti2-N3 (1.791(3), 1.288(4), 1.803(3) A) in 3 that shows strongly activated $\mathrm{N}_{2}$. The Ti1-N1 and Ti2-O5 Mayer bond orders are 0.22 and 0.46 respectively (Figure S26).

Next, we turned our attention to the formation mechanism of 3 with an aid of DFT calculations (Scheme 4). Unlike Liddle's, ${ }^{[11]}$ Chirik's, ${ }^{[10 a]}$ and Kajita's cases, ${ }^{[5 b a]}$ except the complexes 2 and 3, other mononuclear or binuclear titanium $\mathrm{N}_{2}$ complexes (See Scheme S1, S2, and S3), were neither observed nor isolated when 1 was reduced under various reaction conditions under $\mathrm{N}_{2}$ atmosphere or when 2 was stored at low temperature $\left(<-40^{\circ} \mathrm{C}\right)$ (Figure S24). It is reasoned that the high energy barrier for the formation of 6 (Scheme S3) and the sterically congested tert-butyl groups block the formation of 13 even though it is thermodynamically favorable. Therefore, the formation of $\mathbf{3}$ through the reduction of $\mathbf{8}$ or $\mathbf{1 3}$ is unlikely. Instead, we propose that $\mathrm{KOEt}$, formed in the $\mathrm{C}-\mathrm{O}$ bond cleavage of $\mathrm{Et}_{2} \mathrm{O}$ by $\mathrm{KC}_{8}$, binds to complex 5 forming $\mathbf{1 0}$. The compound is further reduced to 12 through the octahedral intermediate 11 . Complex 12 reacts with 5 to form binuclear 15, in analogy to previous reports. ${ }^{[21 \mathrm{a}, 26]}$

Table 1. $\mathrm{NH}_{3}$ and $\mathrm{N}_{2} \mathrm{H}_{4}$ generation from the $\mathrm{N}_{2}$ complex 3

\begin{tabular}{|c|c|c|c|c|c|}
\hline Entry ${ }^{[a, b]}$ & Solvent & Proton source & Reductant & $\mathrm{NH}_{3}(\%)^{[c]}$ & $\begin{array}{c}\mathrm{N}_{2} \mathrm{H}_{4} \\
(\%)^{[c]}\end{array}$ \\
\hline 1 & $\mathrm{Et}_{2} \mathrm{O}$ & $\mathrm{PC} y_{3} \mathrm{HCl}$ & $\mathrm{KC}_{8}$ & 66 & 0.8 \\
\hline 2 & $\mathrm{Et}_{2} \mathrm{O}$ & $\mathrm{PC} y_{3} \mathrm{HI}$ & $\mathrm{KC}_{8}$ & 154 & 1.2 \\
\hline 3 & pentane & $\mathrm{PCy}_{3} \mathrm{HI}$ & $\mathrm{KC}_{8}$ & 105 & 1.1 \\
\hline 4 & toluene & $\mathrm{PCy}_{3} \mathrm{HI}$ & $\mathrm{KC}_{8}$ & 82 & 0.2 \\
\hline 5 & $\mathrm{Et}_{2} \mathrm{O}$ & $\mathrm{HBAr}_{4} \cdot 2 \mathrm{Et}_{2} \mathrm{O}$ & $\mathrm{KC}_{8}$ & 88 & 0.7 \\
\hline 6 & $\mathrm{Et}_{2} \mathrm{O}$ & $\mathrm{HCl}_{2}$ & $\mathrm{KC}_{8}$ & 12 & 0.4 \\
\hline 7 & $\mathrm{Et}_{2} \mathrm{O}$ & $\mathrm{PCy}_{3} \mathrm{HBAr}_{4}$ & $\mathrm{KC}_{8}$ & 83 & 0.1 \\
\hline
\end{tabular}

[a] All reactions were performed under $\mathrm{N}_{2}$ atmosphere, starting at $-78^{\circ} \mathrm{C}$ and gradually warming to $+25^{\circ} \mathrm{C}$ over 34 hours. [b] The yield was averaged over at least 3 runs. [c] Yields based on titanium ion.

With 3 in hand, we investigated its catalytic activity in $\mathrm{N}_{2}$ reduction to ammonia (Table 1 ). A trace amount $(<1 \%)$ of ammonia was detected when quenching 1 with strong acids such as ethereal $\mathrm{HCl}$ or $\mathrm{HBAr}_{4} \cdot \mathrm{Et}_{2} \mathrm{O}$, demonstrating that strong acids can be used as proton donors for 3 . $\mathrm{N}$-based acids may decompose to yield ammonium $\left(\mathrm{NH}_{4}{ }^{+}\right)$in presence of $\mathrm{KC}_{8}$ as found by Liddle and our group, ${ }^{[1,27]}$ therefore, such acids were not considered suitable proton sources. In addition, the stabilizing effect of the potassium ions in $\mathbf{3}$ has to be taken into account for the proper choice of the reducing agent. With these considerations in mind, the catalytic conversion of $\mathrm{N}_{2}$ in $\mathbf{3}$ was examined under various conditions.

In the presence of weak acids such as $\mathrm{PCy}_{3} \mathrm{HCl}$ and $\mathrm{PCy}_{3} \mathrm{HBArF}_{4}\left(\mathrm{BAr}_{4}^{-}=\mathrm{B}\left\{3,5-\left(\mathrm{CF}_{3}\right)_{2} \mathrm{C}_{6} \mathrm{H}_{3}\right\}_{4}^{-}\right)$and reductant $\mathrm{KC}_{8}$, a near-stoichiometric amount (66 and $83 \%$ respectively) of ammonia was synthesized (entries 1 and 7). While switching to strong acids, $\mathrm{HCl} / \mathrm{KC}_{8}$ combination resulted in lowered yield $(12 \%)$ of ammonia (entry 6 ) while a sub-stoichiometric amount $(88 \%)$ of ammonia was obtained when $\mathrm{HBAr}_{4} \cdot 2 \mathrm{Et}_{2} \mathrm{O}$ was used (entry 5). When the fixation proceeded in the presence of $\mathrm{PCy}_{3} \mathrm{HI}$ and $\mathrm{KC}_{8}$ (entry 2), $154 \%$ per $\mathrm{Ti}$ was obtained. When the reduction of ${ }^{3-15} \mathrm{~N}_{2}$ with excess $\mathrm{PCy}_{3} \mathrm{HI} / \mathrm{KC}_{8}$ was performed under ${ }^{15} \mathrm{~N}_{2}$ atmosphere, ${ }^{15} \mathrm{NH}_{4}{ }^{+}$was obtained (Figure $\mathrm{S} 5$ and $\mathrm{S} 6$ ), confirming the $\mathrm{N}_{2}$ gas as the nitrogen source. Notably, reductions performed in diethyl ether proceeded in better yields than those in pentane or toluene (entries 2-4), presumably due to intermediate stabilization by this solvent. In addition to ammonia, a trace amount of hydrazine was observed in all entries. It is speculated that as the reaction proceeds, the number of titanium complexes with the ethoxide ligand increases, inhibiting the regeneration of 3 . Therefore, the catalytic activity would improve if the generation of titanium ethoxide complexes was suppressed. Even though the yields of ammonia formation are lower compared to other catalysts, our results clearly demonstrate that 3 can be used as a catalyst for $\mathrm{N}_{2}$ reduction. 
In summary, we synthesized and characterized unprecedented asymmetric titanium dinitrogen complex $\mathbf{3}$ which adopts TBP-Oh geometries on the Ti centers. The preference of early transition metal complexes to activate dinitrogen as binuclear species and the decrease of the depth of the cavity of the titanium center by switching to octahedral geometry are considered the driving force for the formation of $\mathbf{3}$. In addition, 3 is the first example of a transition metal $\mathrm{N}_{2}$ complex supported by a TPA ligand. Complex 3 produced ammonia in more than stoichiometric amount; $154 \%$ per titanium ion in the presence of an excess amount of $\mathrm{PCy}_{3} \mathrm{HI}$ and $\mathrm{KC}_{8}$, a promising result in the context of $\mathrm{N}_{2}$ reduction catalyst development. Further reactivity studies and optimization of catalytic performance in $\mathrm{N}_{2}$ fixation are currently underway in our laboratory.

\section{Acknowledgements}

This research was supported by Basic Science Research Program through the National Research Foundation of Korea (NRF) funded by the Ministry of Education (NRF2020R1A6A3A01100585 and NRF-2019M1A2A2067940). The $X$-ray crystallography analysis with synchrotron radiation was performed at the Pohang Accelerator Laboratory (PLS-II BL2D $\mathrm{SMC}$ ). We thank Dr. Young Ho Ko (Center for Self-assembly and Complexity, Institute for Basic Science) for assistance with ${ }^{15} \mathrm{~N}$ NMR measurements and Dr. Ewa Pietrasiak and Dr. Youngsuk Kim for helpful discussions.

Keywords: nitrogen fixation $\bullet$ dinitrogen activation $\bullet$ ammonia • amino triphenolate $\cdot$ titanium

[1] M. Appl, in Ammonia, 1. Introduction-Ullmann's Encyclopedia of Industrial Chemistry, Wiley-VCH, Weinheim, 2011, p. 107.

[2] M. P. Shaver, M. D. Fryzuk, Adv. Synth. Catal. 2003, 345, 10611076.

[3] a) I. Rafiqul, C. Weber, B. Lehmann, A. Voss, Energy 2005, 30, 2487-2504; b) Y. Tanabe, Y. Nishibayashi, Coord. Chem. Rev. 2013, 257, 2551-2564; c) Y. Wang, T. J. Meyer, Chem 2019, 5, 496-497.

[4] A. D. Allen, C. V. Senoff, Chem. Commun. 1965, 621-622.

[5] a) L. A. Wickramasinghe, T. Ogawa, R. R. Schrock, P. Müller, J. Am. Chem. Soc. 2017, 139, 9132-9135; b) L. A.

Wickramasinghe, R. R. Schrock, C. Tsay, P. Müller, Inorg. Chem. 2018, 57, 15566-15574; c) D. V. Yandulov, R. R. Schrock, Can. J. Chem. 2005, 83, 341-357; d) T. J. Hebden, R. R. Schrock, M. K. Takase, P. Müller, Chem. Commun. 2012, 48, 1851-1853; e) Y. Lee, N. P. Mankad, J. C. Peters, Nat. Chem. 2010, 2, 558-565; f) E. Lu, B. E. Atkinson, A. J. Wooles, J. T. Boronski, L. R. Doyle, F. Tuna, J. D. Cryer, P. J. Cobb, I. J. Vitorica-Yrezabal, G. F. S. Whitehead, N. Kaltsoyannis, S. T. Liddle, Nat. Chem. 2019, 11, 806-811; g) P. A. Rudd, N. Planas, E. Bill, L. Gagliardi, C. C. Lu, Eur. J. Inorg. Chem. 2013, 2013, 3898-3906; h) R. B. Siedschlag, V. Bernales, K. D. Vogiatzis, N. Planas, L. J. Clouston, E. Bill, L. Gagliardi, C. C. Lu, J. Am. Chem. Soc. 2015, 137, 4638-4641; i) C. J. Weiss, J. D. Egbert, S. Chen, M. L. Helm, R. M. Bullock, M. T. Mock, Organometallics 2014, 33, 2189-2200; j) D. E. Prokopchuk, E. S. Wiedner, E. D. Walter, C. V. Popescu, N. A. Piro, W. S. Kassel, R. M. Bullock, M. T. Mock, J. Am. Chem. Soc. 2017, 139, 9291-9301; k) A. J. Kendall, S. I. Johnson, R. M. Bullock, M. T. Mock, J. Am. Chem. Soc. 2018, 140, 2528-2536; I) Q. Liao, N. Saffon-Merceron, N. Mézailles, ACS Catal. 2015, 5, 6902-6906; m) M. F. Espada, S. Bennaamane, Q. Liao, N. Saffon-Merceron, S. Massou, E. Clot, N. Nebra, M. FustierBoutignon, N. Mézailles, Angew. Chem. Int. Ed. 2018, 57, 12865-12868; n) G. W. Margulieux, Z. R. Turner, P. J. Chirik, Angew. Chem. Int. Ed. 2014, 53, 14211-14215; o) K. C.
MacLeod, D. J. Vinyard, P. L. Holland, J. Am. Chem. Soc. 2014, 136, 10226-10229; p) I. Čorić, B. Q. Mercado, E. Bill, D. J. Vinyard, P. L. Holland, Nature 2015, 526, 96-99; q) S. F. McWilliams, D. L. J. Broere, C. J. V. Halliday, S. M. Bhutto, B. Q. Mercado, P. L. Holland, Nature 2020, 584, 221-226; r) K. C. MacLeod, S. F. McWilliams, B. Q. Mercado, P. L. Holland Chem. Sci. 2016, 7, 5736-5746; s) S. F. McWilliams, K. R. Rodgers, G. Lukat-Rodgers, B. Q. Mercado, K. Grubel, P. L. Holland, Inorg. Chem. 2016, 55, 2960-2968; t) G. P. Connor, N. Lease, A. Casuras, A. S. Goldman, P. L. Holland, J. M. Mayer, Dalton Trans. 2017, 46, 14325-14330; u) S. F. McWilliams, E. Bill, G. Lukat-Rodgers, K. R. Rodgers, B. Q. Mercado, P. L. Holland, J. Am. Chem. Soc. 2018, 140, 8586-8598; v) S. F. McWilliams, P. C. Bunting, V. Kathiresan, B. Q. Mercado, B. M Hoffman, J. R. Long, P. L. Holland, Chem. Commun. 2018, 54, 13339-13342; w) K. Searles, P. J. Carroll, C.-H. Chen, M. Pink, D. J. Mindiola, Chem. Commun. 2015, 51, 3526-3528; x) S. Groysman, D. Villagrán, D. E. Freedman, D. G. Nocera, Chem. Commun. 2011, 47, 10242-10244; y) S. M. Mansell, N. Kaltsoyannis, P. L. Arnold, J. Am. Chem. Soc. 2011, 133, 9036 9051; z) P. L. Arnold, T. Ochiai, F. Y. T. Lam, R. P. Kelly, M. L. Seymour, L. Maron, Nat. Chem. 2020, 12, 654-659; aa) I. Klopsch, M. Kinauer, M. Finger, C. Würtele, S. Schneider, Angew. Chem. Int. Ed. 2016, 55, 4786-4789; ab) C. E. Laplaza, M. J. A. Johnson, J. C. Peters, A. L. Odom, E. Kim, C. C. Cummins, G. N. George, I. J. Pickering, J. Am. Chem. Soc. 1996, 118, 8623-8638; ac) P. J. Hill, L. R. Doyle, A. D. Crawford, W. K. Myers, A. E. Ashley, J. Am. Chem. Soc. 2016, 138, 13521-13524; ad) A. D. Piascik, R. Li, H. J. Wilkinson, J. C. Green, A. E. Ashley, J. Am. Chem. Soc. 2018, 140, 1069110694; ae) D. H. Woen, G. P. Chen, J. W. Ziller, T. J. Boyle, F. Furche, W. J. Evans, J. Am. Chem. Soc. 2017, 139, 1486114864; af) J. P. Shanahan, N. K. Szymczak, J. Am. Chem. Soc. 2019, 141, 8550-8556; ag) J. B. Geri, J. P. Shanahan, N. K. Szymczak, J. Am. Chem. Soc. 2017, 139, 5952-5956; ah) A. McSkimming, W. H. Harman, J. Am. Chem. Soc. 2015, 137, 8940-8943; ai) S. Hinrichsen, A. Kindjajev, S. Adomeit, J. Krahmer, C. Näther, F. Tuczek, Inorg. Chem. 2016, 55, $8712-$ 8722; aj) L. M. Duman, W. S. Farrell, P. Y. Zavalij, L. R. Sita, J. Am. Chem. Soc. 2016, 138, 14856-14859; ak) L. M. Duman, L. R. Sita, J. Am. Chem. Soc. 2017, 139, 17241-17244; al) A. J. Keane, W. S. Farrell, B. L. Yonke, P. Y. Zavalij, L. R. Sita, Angew. Chem. Int. Ed. 2015, 54, 10220-10224; am) M. Falcone, L. Barluzzi, J. Andrez, F. Fadaei Tirani, I. Zivkovic, A. Fabrizio, C. Corminboeuf, K. Severin, M. Mazzanti, Nat. Chem. 2019, 11, 154-160; an) L. D. Field, H. L. Li, P. M. Abeysinghe, M. Bhadbhade, S. J. Dalgarno, R. D. McIntosh, Inorg. Chem. 2019, 58, 1929-1934; ao) S. L. Apps, P. W. Miller, N. J. Long, Chem. Commun. 2019, 55, 6579-6582; ap) T. Suzuki, K. Fujimoto, Y. Takemoto, Y. Wasada-Tsutsui, T. Ozawa, T. Inomata, M. D. Fryzuk, H. Masuda, ACS Catal. 2018, 8, 3011 3015; aq) A. Katayama, T. Ohta, Y. Wasada-Tsutsui, T. Inomata, T. Ozawa, T. Ogura, H. Masuda, Angew. Chem. Int Ed. 2019, 58, 11279-11284; ar) A. Simonneau, R. Turrel, L. Vendier, M. Etienne, Angew. Chem. Int. Ed. 2017, 56, 1226812272; as) A. Bouammali, C. Bijani, L. Vendier, M. Etienne, A. Simonneau, Eur. J. Inorg. Chem. 2020, 2020, 1423-1427; at) A. Coffinet, D. Specklin, L. Vendier, M. Etienne, A. Simonneau, Chem. Eur. J. 2019, 25, 14300-14303; au) Q. J. Bruch, G. P. Connor, C.-H. Chen, P. L. Holland, J. M. Mayer, F. Hasanayn, A. J. M. Miller, J. Am. Chem. Soc. 2019, 141, 20198-20208; av) Z.-J. Lv, Z. Huang, W.-X. Zhang, Z. Xi, J. Am. Chem. Soc. 2019, 141, 8773-8777; aw) P. Wang, I. Douair, Y. Zhao, S. Wang, J. Zhu, L. Maron, C. Zhu, Angew. Chem. Int. Ed. 2021 60, 473-479; ax) Y. Lee, F. T. Sloane, G. Blondin, K. A. Abboud, R. García-Serres, L. J. Murray, Angew. Chem. Int. Ed. 2015, 54, 1499-1503; ay) L. J. Murray, W. W. Weare, J. Shearer, A. D. Mitchell, K. A. Abboud, J. Am. Chem. Soc. 2014 136, 13502-13505; az) R. B. Ferreira, B. J. Cook, B. J. Knight, V. J. Catalano, R. García-Serres, L. J. Murray, ACS Catal. 2018, 8, 7208-7212; ba) Y. Kokubo, C. Yamamoto, K. Tsuzuki, T. Nagai, A. Katayama, T. Ohta, T. Ogura, Y. Wasada-Tsutsui, Y. Kajita, S. Kugimiya, H. Masuda, Inorg. Chem. 2018, 57, 11884-11894; bb) M. Reiners, D. Baabe, K. Münster, M.-K. Zaretzke, M. Freytag, P. G. Jones, Y. Coppel, S. Bontemps, I. 
d. Rosal, L. Maron, M. D. Walter, Nat. Chem. 2020, 12, 740746; bc) H. Kawaguchi, T. Matsuo, Angew. Chem. Int. Ed. 2002, 41, 2792-2794; bd) F. Akagi, T. Matsuo, H. Kawaguchi, Angew. Chem. Int. Ed. 2007, 46, 8778-8781; be) Y. Ishida, H. Kawaguchi, J. Am. Chem. Soc. 2014, 136, 16990-16993; bf) J. Li, J. Yin, G.-X. Wang, Z.-B. Yin, W.-X. Zhang, Z. Xi, Chem. Commun. 2019, 55, 9641-9644; bg) T. Toda, S. Suzuki, S. Kuwata, Chem. Commun. 2019, 55, 1028-1031; bh) C. H. Arnett, T. Agapie, J. Am. Chem. Soc. 2020, 142, 10059-10068; bi) D. Sorsche, M. E. Miehlich, K. Searles, G. Gouget, E. M. Zolnhofer, S. Fortier, C.-H. Chen, M. Gau, P. J. Carroll, C. B. Murray, K. G. Caulton, M. M. Khusniyarov, K. Meyer, D. J. Mindiola, J. Am. Chem. Soc. 2020, 142, 8147-8159; bj) S. Suzuki, Y. Ishida, H. Kameo, S. Sakaki, H. Kawaguchi, Angew. Chem. Int. Ed. 2020, 59, 13444-13450; bk) M. Pucino, F. Allouche, C. P. Gordon, M. Wörle, V. Mougel, C. Copéret Chem. Sci. 2019, 10, 6362-6367; bl) T. Liu, M. R. Gau, N. C. Tomson, J. Am. Chem. Soc. 2020, 142, 8142-8146.

[6] a) D. V. Yandulov, R. R. Schrock, Science 2003, 301, 76-78; b) D. G. H. Hetterscheid, B. S. Hanna, R. R. Schrock, Inorg. Chem. 2009, 48, 8569-8577; c) T. Munisamy, R. R. Schrock, Dalton Trans. 2012, 41, 130-137; d) R. R. Schrock, Acc. Chem. Res. 2005, 38, 955-962; e) D. V. Yandulov, R. R. Schrock, J. Am. Chem. Soc. 2002, 124, 6252-6253; f) D. V. Yandulov, R. R. Schrock, Inorg. Chem. 2005, 44, 1103-1117.

[7] a) J. S. Anderson, J. Rittle, J. C. Peters, Nature 2013, 501, 8487; b) S. E. Creutz, J. C. Peters, J. Am. Chem. Soc. 2014, 136 1105-1115; c) T. J. Del Castillo, N. B. Thompson, J. C. Peters, J. Am. Chem. Soc. 2016, 138, 5341-5350; d) M. J. Chalkley, T. J. Del Castillo, B. D. Matson, J. P. Roddy, J. C. Peters, ACS Cent. Sci. 2017, 3, 217-223; e) T. M. Buscagan, P. H. Oyala, J. C. Peters, Angew. Chem. Int. Ed. 2017, 56, 6921-6926.

[8] a) Y. Ashida, K. Arashiba, K. Nakajima, Y. Nishibayashi, Nature 2019, 568, 536-540; b) K. Arashiba, Y. Miyake, Y. Nishibayashi, Nat. Chem. 2011, 3, 120-125; c) H. Tanaka, A. Sasada, T. Kouno, M. Yuki, Y. Miyake, H. Nakanishi, Y. Nishibayashi, K. Yoshizawa, J. Am. Chem. Soc. 2011, 133, 3498-3506; d) S. Kuriyama, K. Arashiba, K. Nakajima, H. Tanaka, N. Kamaru, K. Yoshizawa, Y. Nishibayashi, J. Am. Chem. Soc. 2014, 136 9719-9731; e) K. Arashiba, E. Kinoshita, S. Kuriyama, A. Eizawa, K. Nakajima, H. Tanaka, K. Yoshizawa, Y. Nishibayashi, J. Am. Chem. Soc. 2015, 137, 5666-5669; f) S. Kuriyama, K. Arashiba, K. Nakajima, Y. Matsuo, H. Tanaka, K. Ishii, K. Yoshizawa, Y. Nishibayashi, Nat. Commun. 2016, 7 , 12181; g) A. Eizawa, K. Arashiba, H. Tanaka, S. Kuriyama, Y. Matsuo, K. Nakajima, K. Yoshizawa, Y. Nishibayashi, Nat. Commun. 2017, 8, 14874; h) Y. Sekiguchi, K. Arashiba, H. Tanaka, A. Eizawa, K. Nakajima, K. Yoshizawa, Y Nishibayashi, Angew. Chem. Int. Ed. 2018, 57, 9064-9068.

[9] R. Imayoshi, K. Nakajima, Y. Nishibayashi, Chem. Lett. 2017, 46, 466-468.

[10] a) T. E. Hanna, E. Lobkovsky, P. J. Chirik, J. Am. Chem. Soc. 2004, 126, 14688-14689; b) T. E. Hanna, E. Lobkovsky, P. J. Chirik, J. Am. Chem. Soc. 2006, 128, 6018-6019.

[11] L. R. Doyle, A. J. Wooles, L. C. Jenkins, F. Tuna, E. J. L. McInnes, S. T. Liddle, Angew. Chem. Int. Ed. 2018, 57, 63146318.

[12] P. Ghana, F. D. van Krüchten, T. P. Spaniol, J. van Leusen, P. Kögerler, J. Okuda, Chem. Commun. 2019, 55, 3231-3234.

[13] a) Y. Nakanishi, Y. Ishida, H. Kawaguchi, Angew. Chem. Int. Ed. 2017, 56, 9193-9197; b) Y. Nakanishi, Y. Ishida, H. Kawaguchi, Dalton Trans. 2018, 47, 6903-6907; c) T. Kurogi, Y. Ishida, H. Kawaguchi, Chem. Commun. 2013, 49, 1175511757.

[14] a) M. M. Guru, T. Shima, Z. Hou, Angew. Chem. Int. Ed. 2016, 55, 12316-12320; b) Z. Mo, T. Shima, Z. Hou, Angew. Chem. Int. Ed. 2020, 59, 8635-8644; c) B. Wang, G. Luo, M. Nishiura, S. Hu, T. Shima, Y. Luo, Z. Hou, J. Am. Chem. Soc. 2017, 139, 1818-1821.

[15] Y. Ohki, K. Uchida, M. Tada, R. E. Cramer, T. Ogura, T. Ohta, Nat. Commun. 2018, 9, 3200

[16] a) D. Y. Bae, Y. Kim, J. Cha, E. Lee, Coord. Chem. Rev. 2020 419, 213402; b) G. Licini, M. Mba, C. Zonta, Dalton Trans. 2009, 5265-5277.
[17] A. J. Nielson, C. Shen, J. M. Waters, Polyhedron 2006, 25, 2039-2054.

[18] M. Keilwerth, L. Grunwald, W. Mao, F. W. Heinemann, J. Sutter, E. Bill, K. Meyer, J. Am. Chem. Soc. 2021, 143, 14581465.

[19] a) M. Kol, R. R. Schrock, R. Kempe, W. M. Davis, J. Am. Chem. Soc. 1994, 116, 4382-4390; b) M. B. O'Donoghue, W. M. Davis, R. R. Schrock, Inorg. Chem. 1998, 37, 5149-5158; c) G. E. Greco, R. R. Schrock, Inorg. Chem. 2001, 40, 3861-3878; d) D. V. Yandulov, R. R. Schrock, A. L. Rheingold, C Ceccarelli, W. M. Davis, Inorg. Chem. 2003, 42, 796-813.

[20] a) D. Y. Bae, G. S. Park, N. Ko, K.-s. Son, E. Lee, Dalton Trans. 2019, 48, 9617-9624; b) H. K. Ryu, D. Y. Bae, H. Lim, E. Lee, K.-s. Son, Polym. Chem. 2020, 11, 3756-3761.

[21] a) M. D. Fryzuk, S. A. Johnson, Coord. Chem. Rev. 2000, 200202, 379-409; b) F. Studt, F. Tuczek, J. Comput. Chem. 2006 27, 1278-1291; c) D. Singh, W. R. Buratto, J. F. Torres, L. J. Murray, Chem. Rev. 2020, 120, 5517-5581.

[22] a) R. Duchateau, S. Gambarotta, N. Beydoun, C. Bensimon, J. Am. Chem. Soc. 1991, 113, 8986-8988; b) N. Beydoun, R. Duchateau, S. Gambarotta, J. Chem. Soc., Chem. Commun. 1992, 244-246; c) G. Bai, P. Wei, D. W. Stephan, Organometallics 2006, 25, 2649-2655; d) W. A. Chomitz, J. Arnold, Chem. Commun. 2007, 4797-4799; e) J. R. Hagadorn, J. Arnold, Organometallics 1998, 17, 1355-1368.

[23] a) A. Mommertz, R. Leo, W. Massa, K. Harms, K. Dehnicke, Z Anorg. Allg. Chem. 1998, 624, 1647-1652; b) C. A. Bradley, L. F. Veiros, D. Pun, E. Lobkovsky, I. Keresztes, P. J. Chirik, J. Am. Chem. Soc. 2006, 128, 16600-16612; c) T. Beweries, U. Jäger-Fiedler, M. A. Bach, V. V. Burlakov, P. Arndt, W Baumann, A. Spannenberg, U. Rosenthal, Organometallics 2007, 26, 3000-3004

[24] S. A. Cortes, M. A. Muñoz Hernández, H. Nakai, I. CastroRodriguez, K. Meyer, A. R. Fout, D. L. Miller, J. C. Huffman, D. J. Mindiola, Inorg. Chem. Commun. 2005, 8, 903-907.

[25] K. Hadjiivanov, M. Mihaylov, D. Panayotov, E. Ivanova, K. Chakarova, in Spectroscopic Properties of Inorganic and Organometallic Compounds: Volume 45, Vol. 45, The Royal Society of Chemistry, 2014, pp. 43-78.

[26] J. M. Smith, A. R. Sadique, T. R. Cundari, K. R. Rodgers, G. Lukat-Rodgers, R. J. Lachicotte, C. J. Flaschenriem, J. Vela, P. L. Holland, J. Am. Chem. Soc. 2006, 128, 756-769.

[27] J. Cha, H. Kwon, H. Song, E. Lee, Dalton Trans. 2020, 49, 12945-12949. 


\section{Entry for the Table of Contents}

Insert graphic for Table of Contents here.

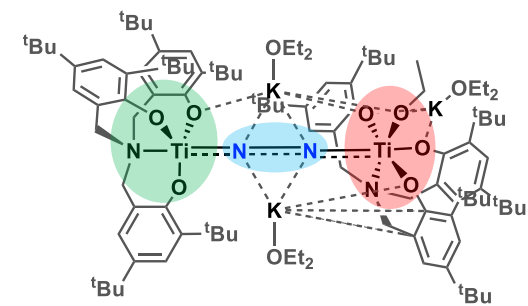

- First example of $M(T B P)-N_{2}-M(O h)$ geometries

- First triphenolamine (TPA) based $N_{2}$ complex

- $\mathrm{N}_{2}$ reduction by $\mathrm{K} / \mathrm{Ti}$

- $\mathrm{NH}_{3}$ synthesis in the presence of $\mathrm{H}^{+} / \mathrm{e}^{-}$(up to $154 \%$ )

We report the first example of a binuclear $\mathrm{Ti}-\mathrm{N}_{2}$ complex with triphenolamine that adopts trigonal bipyramidal and octahedral geometries on the Ti centers. The activated $\mathrm{N}_{2}$ was reduced to ammonia with $154 \%$ yield (per $\mathrm{Ti}$ atom) in the presence of proton and electron sources. 